Perspective

\title{
Life skills training as a promising preventive strategy of self-harm and other common problems in adolescents: low and lower-middle-income country perspective
}

Pushpakumara PHGJ ${ }^{1}$,

${ }^{1}$ Department of Family Medicine, Faculty of Medicine and Allied Sciences, Rajarata University of Sri Lanka.

Copyright: (C) 2019 Pushpakumara. (c) (1) This is an open-access article distributed under the Creative Commons Attribution License, which permits unrestricted use, distribution, and reproduction in any medium provided the original work is properly cited.

Funding: None

Competing interests: None

$\bowtie$ Correspondence: janakatechno@yahoo.com

https://orcid.org/0000-0002-8680-4397

Cite this article as: Pushpakumara PHGJ, Life skills training as a promising preventive strategy of self-harm and other common problems in adolescents: low and lower-middle-income country perspective.

Anuradhapura Medical Journal 2019;13 (1):1-3.

DOI: http://doi.org/10.4038/amj.v13i1.7665

\section{Background}

Life Skills have been variously defined. Most available definitions contain elements of the World Health Organization's (WHO) statement which indicates that life skills are the "psychosocial abilities for adaptive and positive behaviour that enable individuals to deal effectively with the demands and challenges of everyday life" (1). A list of 10 life skills is described as generic life skills for psychosocial competence, identified by WHO as core life skills applicable across a wide range of contexts in daily life and risk situations. These life skills include self-awareness, empathy, communication skills, interpersonal skills, decisionmaking, problem-solving, creative thinking, critical thinking, coping with emotions and coping with stress (2).

Adolescence is a transitional phase of life in which one-fifth experiences mental health problems, including anxiety and depression, and suicidal behaviours ( $\underline{3}$ ). Low levels of mental wellbeing are a predictor of psychological problems and mortality (4). Globally suicide is the third leading cause of death in young people, with a higher burden in low and lower-middle-income countries (LMIC) (ㅁ) ). In 2009, suicide accounted for one in fourteen adolescents (ㅁ). Alcohol, illicit drug use and unsafe sex are the main risk factors for incident disabilityadjusted life-years in adolescents (7). Substance use is increasing in LMIC ( $\underline{8}$ ) and contributes to the increasing incidents of suicidal attempts (ㅁ). In LMIC, these developmental and socio-economic vulnerabilities have resulted in adolescents experiencing a disproportionately higher burden of reproductive and maternal morbidity and mortality (10).

Individuals with a higher risk for suicide are often poor at problem-solving skills and dealing with interpersonal problems (11). It was reported that the inability to cope with negative feelings, emotions

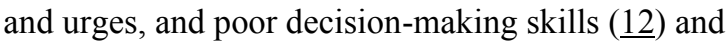
lack of skills necessary to deal with their problems (13) were the leading causes for suicidal behaviour. In rural north-central of Sri Lanka, self-poisoning was labeled as a preferred method of dealing with difficult situations in most of the adolescents (14). Similarly, in southern Sri Lanka it was labelled as a 'quick fix' to difficult interpersonal circumstances $(\underline{15})$.

Adolescents with better psycho-social competencies contributing to creating resilient adolescents who can cope with daily challenges and lead productive lives (ㅁ). However, in general, life skills is a less explored entity in suicidology $(\underline{16})$.

An interventional study reported that life skills training improved the negative cognitive-affective states and hopelessness, the major mediating 
variable associated with suicide (17). Although there are no direct findings, researchers are confident about the reduction of suicide probability with life skills training (17).

The life-skills and life-skills training came on to the stage with recent changes in the family structure and functioning in LMIC ( $\underline{18})$, specifically Indian subcontinent countries which are contributed to a considerable proportion of suicides globally (19). The extended family structure changed to a nuclear family. The number of children in a family drastically reduced over the last three to four decades $(\underline{18})$. Parenting patterns were changed and the number of hours available to be with the children was shrunken. The quality of the family relationships was reduced and family bonds were loosened gradually. This is a kind of change that can be labelled as an inevitable transformation with the changing socio-economic environment in LMIC. Moreover, in recent years, a further distancing of family relationships can be expected parallel to the increase in screen time. Similarly, this can be labelled as an inevitable change with the so-called development of technology. However, these transformations disrupt the traditional flow of life experiences, which happened within the household. The vacuum created by that disruption demands the bridging gap through the life-skills training, preferably included in the formal education curriculum.

In adolescents, positive social relations are among the most reliable protective factors from suicidal behaviour (20). School-based life-skills interventions in Western countries where parents are actively involved have demonstrated increased parental care and reduced substance abuse, reduced family conflict, improved family support, reductions in suicide associated risk behaviours among youth (21), and enhanced parent communication skills (ability to communicate with youth in distress e.g. about suicide) $(\underline{20}, \underline{22}, \underline{23})$. A decade ago, a similar finding was observed through a population-based intervention, in India (24).

Hence, without a doubt, school-based adolescent life-skills training can be recommended as a promising preventive strategy of self-harm and other common problems in LMIC adolescents.

\section{References}

1.WHO Life skills education: planning for research. In. Geneva, Switzerland: Division of Mental Health and Prevention of Substance Abuse, World Health Organization; 1996.

2.WHO (Regional Office for South-East Asia) Regional framework for introducing life-skills education to promote the health of adolescents. In. New Delhi, India: World Health Organization - Regional Office for SouthEast Asia; 2001.

3.WHO. Adolescent mental health - Mapping actions of nongovernmental organizations and other international development organizations In. Geneva: WHO; 2012.

4.Huppert F, Whittington, JE. Evidence for the independence of positive and negative wellbeing: implications for quality of life assessment. British Journal of Health Psychology. 2003;8(Pt 1):107-122.

5.Wasserman D, Cheng Q, Jiang G-X: Global suicide rates among young people aged 15-19. World Psychiatry. 2005;4:114-120.

6.Patton GC, Coff ey C, Sawyer SM, et al. Global patterns of mortality in young people: a systematic analysis of population health data. The Lancet. 2009;374(9693):881-892.

7.Gore F, Bloem PJ., Patton GC., et al. Global burden of disease in young people aged 10-24 years: a systematic analysis. The Lancet.2011;377(9783):2093-2102.

8.Anderson P: Global use of alcohol, drugs and tobacco. Drug and Alcohol Review. 2006;25(6):489-502.

9.Vijayakumar L, Kumar, MS, Vijayakumar, V.Substance use and suicide. Current Opinion in Psychiatry. 2011;24(3):197-202. 
10.Viner R, Coffey C, Mathers C. et al. 50-year mortality trends in children and young people: a study of 50 lowincome, middle-income, and high-income countries. The Lancet. 2011;377(9772):1162-1174.

11.Schlebusch L. Suicide prevention: A proposed national strategy for South Africa. African Journal of Psychiatry. 2012;15(6):436-440.

12.Ratnayeke L. Suicide in Sri Lanka. In: Suicide Prevention. Edited by Kosky ea. New York: Plenum Press; 1998: 139.

13.de Silva HJ, Kasturiarachchi N, Seneviratne SL et al. Suicide in Sri Lanka: points to ponder. Ceylon Medical Journal.2000; 45:17-24.

14.Eddleston M, Sheriff MHR, Hawton K. Deliberate self harm in Sri Lanka: an overlooked tragedy in the developing world. British Medical Journal.1998;317:133-142.

15.Senadheera C. Deliberate self-harm of children and adolescents: a hospital based study. In: Suicide in Sri Lanka: Past, Present and Future Transformations: 2013; University of Colombo: Department of Sociology, University of Colombo; 2013.

16.Jegannathan B, Kullgren G. Gender differences in suicidal expressions and their determinants among young people in Cambodia, a post-conflict country. BMC psychiatry.2011;11:47.

17.LaFromboise T, Howard-Pitney B. The Zuni life skills development curriculum: Description and evaluation of a suicide prevention program. Journal of Counseling Psychology. 1995;42(4):479-486.

18.Jones GW.Changing family sizes, structures and functions in Asia. Asia-Pacific Population Journal.2012;27(1):83-102.

19.Khan MM.Suicide on the Indian Subcontinent. Crisis. 2002;23(3):104-107.

20.De Silva S, Parker A, Purcell R, et al. Mapping the evidence of prevention and intervention studies for suicidal and self-harming behaviors in young people. Crisis. 2013;34(4):223-232.

21.Hooven C, Walsh E, Pike KC, Herting JR. Promoting CARE: including parents in youth suicide prevention. Family and Community Health. 2012;35(3):225-235.

22.Katz C, Bolton SL, Katz LY, et al. A systematic review of school-based suicide prevention programs. Depression and Anxiety. 2013;30(10):1030-1045.

23.Wasserman D, Hoven CW, Wasserman C et al. School-based suicide prevention programmes: the SEYLE cluster-randomised, controlled trial. The Lancet 2015;385(9977):1536-1544.

24. Balaji M, Andrews T, Andrew G, Patel V.The acceptability, feasibility, and effectiveness of a populationbased intervention to promote youth health: an exploratory study in Goa, India. Journal of Adolescent Health. $2011 ; 48(5): 453-460$.

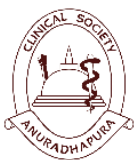

Submit your next manuscript to

Anuradhapura

Medical Journal

Submit your manuscript at

http://amj.sljol.info/ 